\title{
Karst landscapes of China: patterns, ecosystem processes and services
}

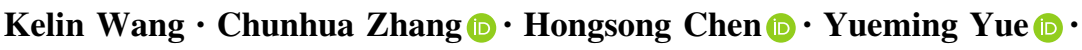 \\ Wei Zhang $\mathbb{D} \cdot$ Mingyang Zhang $(\mathbb{D} \cdot$ Xiangkun Qi $(\mathbb{D} \cdot$ Zhiyong Fu
}

Received: 24 April 2019/Accepted: 23 September 2019/Published online: 28 October 2019

(C) The Author(s) 2019

\begin{abstract}
Context The karst region of southwestern China, one of the largest continuous karsts in the world, is known for its unique landscapes and rich biodiversity. This region has suffered severe environmental degradation (e.g., vegetation cover loss, soil erosion and biodiversity loss). In recent decades, Chinese governments at different levels have initiated several ecological programs (e.g., Green for Grain, Mountain Closure) to restore the degraded environment and to alleviate poverty.

Objectives This study summarizes landscape studies of karst landscapes patterns, their dynamics and interactions among landscape pattern, hydrological processes and ecosystem services (ES).
\end{abstract}

K. Wang $(\bowtie) \cdot$ C. Zhang $\cdot$ H. Chen ·

Y. Yue - W. Zhang - M. Zhang - X. Qi - Z. Fu

Key Laboratory for Agro-ecological Processes in Subtropical Region, Institute of Subtropical Agriculture, Chinese Academy of Sciences, Hunan 410125, China e-mail: kelin@isa.ac.cn

K. Wang - C. Zhang $\cdot$ H. Chen - Y. Yue ·

W. Zhang · M. Zhang · X. Qi · Z. Fu

Huanjiang Observation and Research Station for Karst

Ecosystem, Chinese Academy of Science, Huanjiang,

Guangxi 547100, China

C. Zhang

Department of Geography and Geology, Algoma

University, Sault Ste. Marie, ON P6A2G4, Canada
Methods We conducted a systematic literature review of science and land use policy to identify knowledge gaps and recommend future research and policy directions.

Results Karst landscapes have experienced rapid turnover in recent decades due largely to the overlap of intense human activity on the fragile karst ecosystems. Many studies have comprehensively examined hydrology, soil processes and ecosystem services (ES) and their relationships with landscape pattern. Most of these studies have found that karst ecosystems recover with improved ES. However, the importance of epikarst in hydrological and soil processes, intense anthropogenic disturbance and landscape heterogeneity in landscape models remains elusive.

Conclusions Future research should focus on indepth examination and modelling of karst specific hydrological and soil processes, investigating relationships between climatic change, landscape change, ecological processes, and region-specific ES assessments. Results from such research should provide the necessary scientific support for a comprehensive, national karst rocky desertification treatment project (Stage II) and poverty alleviation initiatives.

Keywords Southwestern China $\cdot$ Landscape pattern $\cdot$ Karst rocky desertification $\cdot$ Ecological engineering $\cdot$ Landscape sustainability $\cdot$ Ecosystem services 


\section{Introduction}

Surface and near-surface carbonate outcrops constitute approximately $20 \%$ of the world's dry and ice-free land area (Ford and Williams 2007). Karst landscapes (e.g., caverns, springs, towers, sinkhole plains) developed in these carbonate-dominated regions are attractive for tourists, but their heterogeneity is challenging for agricultural development and other human activities. The humid tropical and subtropical karst region in southwestern China, one of the largest continuous karsts in the world, is unique for its special landscapes (e.g., towers (fenglin), pinnacles (shilin), cones (fengcong), giant collapse depressions (tiankeng), gorges, caverns) and rich biodiversity. However, a large portion of the region has experienced significant environmental degradation in the twentieth century due to unsustainable agricultural development, high and increasing population pressure and relatively low population carrying capacity ( $\mathrm{Li}$ et al. 2004a; Cao et al. 2008). Increasing population and low land productivity have triggered agricultural expansion to marginal cropland on slopes and ridges. This had resulted in severe vegetation cover loss and soil erosion. Consequently, karst rocky desertification (KRD) has appeared, resulting in previously vegetated landscapes being transformed into bare rock (Yuan and Cai 1988; Jiang et al. 2014a).

Environmental conditions in the karst region significantly affect the ecological security of southern China. Beginning in the early twenty-first century, Chinese governments at various levels initiated ecological engineering projects (e.g., Green for Grain, Mountain Closure and Environmental Migration) to alleviate poverty and to recover the degraded environment. Chinese researchers, in collaboration with governmental agencies and local residents, also designed, tested and implemented a variety of KRD restoration techniques (e.g., Jiang et al. 2014b; Wang et al. 2016a, b, c). Approximately during the same period, many farmers in this region migrated to urban areas and coastal regions for better job opportunities that helped to lessen regional population pressure. Information from various sources indicate that the karst environment improved in the past 20 years (Zhang et al. 2017). Specifically, a significant increase in aboveground biomass (on average $\geq 4.0 \%$ over 0.9 million $\mathrm{km}^{2}$ ) between 1999 and 2012 had occurred at the regional scale, which makes up approximately $5 \%$ of global areas with increasing biomass (Brandt et al. 2018; Tong et al. 2018). Aerial cover of KRD in southwestern China has decreased from 129,600 $\mathrm{km}^{2}$ in 2006 (10.8\% of the land area) to $100,700 \mathrm{~km}^{2}$ in 2016 (8.4\% of the land area).

Human intervention in environmental recovery had accelerated landscape pattern change and consequently affected energy flow, nutrient and hydrological cycles, pollutant distribution, species migration and the dispersion and provision of ecosystem services (ES). Many studies of karst landscape patterns and ecological processes have been published over the past three decades. A search of CNKI.net, a widely searched database for academic research in China, using the terms "karst" and "landscape" in August 2018 returned 1272 peer-reviewed journal articles published in Chinese. At least 50 papers have been published annually since 2006. However, there are no studies examining karst landscape dynamics. This study addresses this gap by summarizing karst landscape pattern changes and the relationships with ecological processes and identifies future research directions through a systematic literature review.

\section{Key characteristics of the karst landscape in southwestern China}

The karst region spans eight provinces in southwestern China, centred in the Yunnan-Guizhou Plateau and southern hilly regions (Fig. 1). The total area of carbonate outcrops is $540,000 \mathrm{~km}^{2} ; 45.2 \%$ of the regional land area (Fan et al. 2011). About 292 counties $(38.8 \%)$ in the region have over $30 \%$ cover of carbonate rock outcrops (Cao et al. 2004). This is a region with a variety of landforms including mountains, hills, valleys, basins and plains. Areas with elevation ranges lower than $500 \mathrm{~m}$, between 500 and 1000, between 1000 and $2000 \mathrm{~m}$, between 2000 and 3000 , or higher than $3000 \mathrm{~m}$ are $37.3 \%, 18.1 \%$, $21.6 \%, 9.1 \%$, and $13.9 \%$ of the land area respectively.

Continuous tectonic uplift, denudation, erosion and deposition over millions of years have resulted in a variety of intricately mosaicked karstic landscapes (Wang et al. 2004). Carbonate rocks in the region are much older than their counterparts in southern and central Europe and eastern North America and have undergone stronger petrification; the rocks are mechanically rigid and tend to break under 

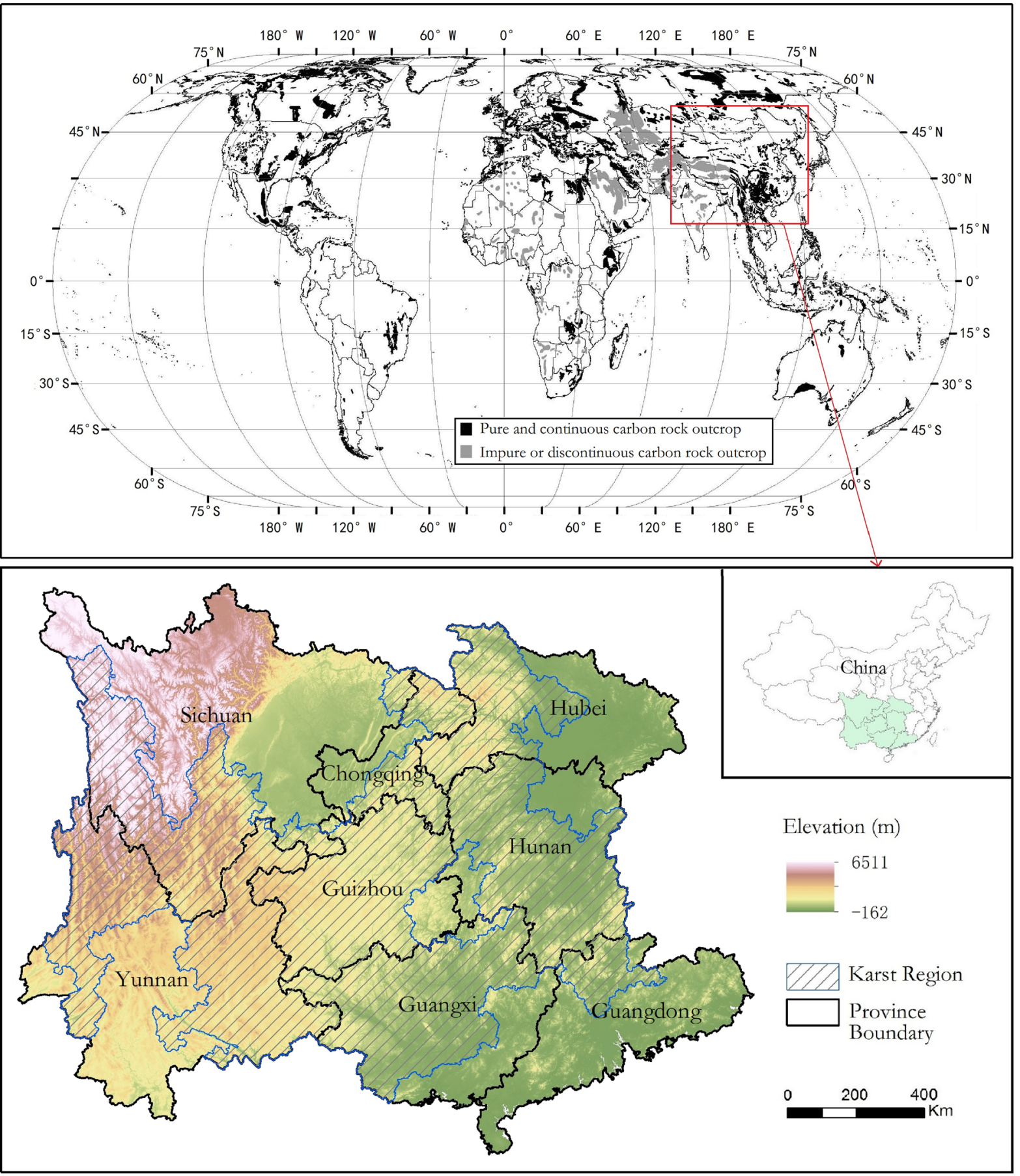

Fig. 1 The karst region in southwestern China. Carbonate rock outcrop data was accessed from https://www.fos.auckland.ac.nz/our_ research/karst/index.html (Ford and Williams 2007)

geotectonic action (Wang et al. 2004). As well, there are a variety of carbonate rock assemblages in this region; homogenous carbonate rock (limestone, dolomite and mixed), carbonate rock intercalated with clastic rock and carbonate/clastic rock alternations (Wang et al. 2004). Lithology differences affect the 
development of landforms and soil erosion ( $\mathrm{Li}$ et al. 2004c). This region was also not affected by glaciation processes because of its southern location. Strong, uneven, chemical dissolution ensures that large areas of karst terrain are heterogeneous and fragmented. Consequently, even on the Yunnan-Guizhou Plateau, deep cut valleys and rivers are relatively common and there is steep variation in elevation.

Soil formation in the region is very slow because of its unique carbonate bedrock. Although weathering and pedogenesis are very active in the region because of the warm and moist climate, the generally very small percentage of insoluble pure carbonate rock components (4\% on average) make the soil formation process slow (Wang et al. 2004). The speed of soil formation is 10 to 40 times less than its counterparts with similar climates; 250,000 to 850,000 and 630,000 to $7,880,000$ years are needed to form $10 \mathrm{~cm}$ of soil in the karst region of Guangxi and Guizhou respectively (Yuan and Cai, 1988; Cao et al. 2004). Correspondingly, soils developed in this karstic context are generally thin (Wang et al. 2004).

That most karst soils have direct contact with bedrock (i.e., lack a $\mathrm{C}$ horizon) makes these soils highly susceptible to erosion under intense precipitation events (Cao et al. 2004). Soils in the region generally have high $\mathrm{pH}$ and calcium content and are low in N, P and other nutrients (Cao et al. 2003). The fragmented landscape (i.e., high percentage of rock outcrop and large slope variation) dictates that karst soils in many areas are discontinuous. Thin, discontinuous soil makes vegetation distribution in the karst region very patchy and less resistant to disturbance. Once degraded, it may take decades or centuries to recover karst forests (Cao et al. 2004). Agricultural activities have had significant impacts on soil conditions and landscape patterns. The removal of the native vegetation for agricultural production changed the hydrological cycles in epikarst, created heterogeneous landscapes and environmental degradation (Zhang et al. 2012a).

The dominant tropical and subtropical monsoon climate in southwestern China has shaped the various karst landforms (e.g., towers, cones, basins, hills, valleys; Fig. 2) and ecosystems. There is abundant precipitation (1000-2000 $\mathrm{mm}$ annually) across the region (Fan et al. 2011; Song et al. 2014). Average annual temperature of this region ranges between 14 and $24{ }^{\circ} \mathrm{C}$ (Fan et al. 2011). Large spatial variation in temperature and precipitation are found here due to elevation and latitude. Similarly, seasonal variation in precipitation is common in the region with more than $60 \%$ occurring as rainfall between June and August (Song et al. 2014). Although there is generally abundant precipitation in the region, surface runoff may charge the ground water system through bedrock fractures, sinkholes, and underground conduit systems. Spatially, ground water resources constitute about $41 \%$ to $83 \%$ of the total (Cao et al. 2004). Nevertheless, it is challenging for vegetation and people to make use of ground water because of the generally low water table. As a result, droughts may occur during the spring and autumn months. The increasing frequency of extreme precipitation events under global climate change (GCC) scenarios may pose a further challenge for soil preservation and vegetation recovery.

The unique geological setting and soil properties significantly affect physiological traits and the spatial distribution of karst vegetation. Many vegetation species in karst regions are drought-prone (xeophile), are calcium tolerant (calciphile), and have thick cuticle and wax-coatings (Zhou, 1997). Dominant vegetation may develop deep penetrating roots or shallow, extensive roots to exploit water from a variety of sources (Nie et al. 2014). Furthermore, the combination of landform types and terrain (aspect, slope, slope position) create abundant community niches; dry or wet (rock surface $v s$ depression), thin or thick soil (peak/ridge $v s$ depression) and nutrient poor or rich (rock surface, peak/ridge $v s$ rock fissure/crack, rock channel) (Zhu, 1993). This further adds to the strong, regional landscape heterogeneity.

Southwestern China is well known for its rich biodiversity and for the world's largest old-growth subtropical karst forest, dominated by evergreen and deciduous broadleaf trees (Zhu 2007). Consequently, the region has rich plant biodiversity, comprising $30-40 \%$ of regional (southern China) flora. There are many nationally and internationally protected plants and animal species. For example, 123 vegetation species $(31.6 \%$ of the total) were on the first iteration of the nationally protected vegetation species list (Fan et al. 2011). In the Mulun Karst Forest, Guangxi, there are 539 plant, vertebrate, insect and large fungi species, of which 31 are nationally protected (Jiang 1995). In Libo Karst, Guizhou, 121 vegetation species were on the IUCN Red List (Zhu 2007). 

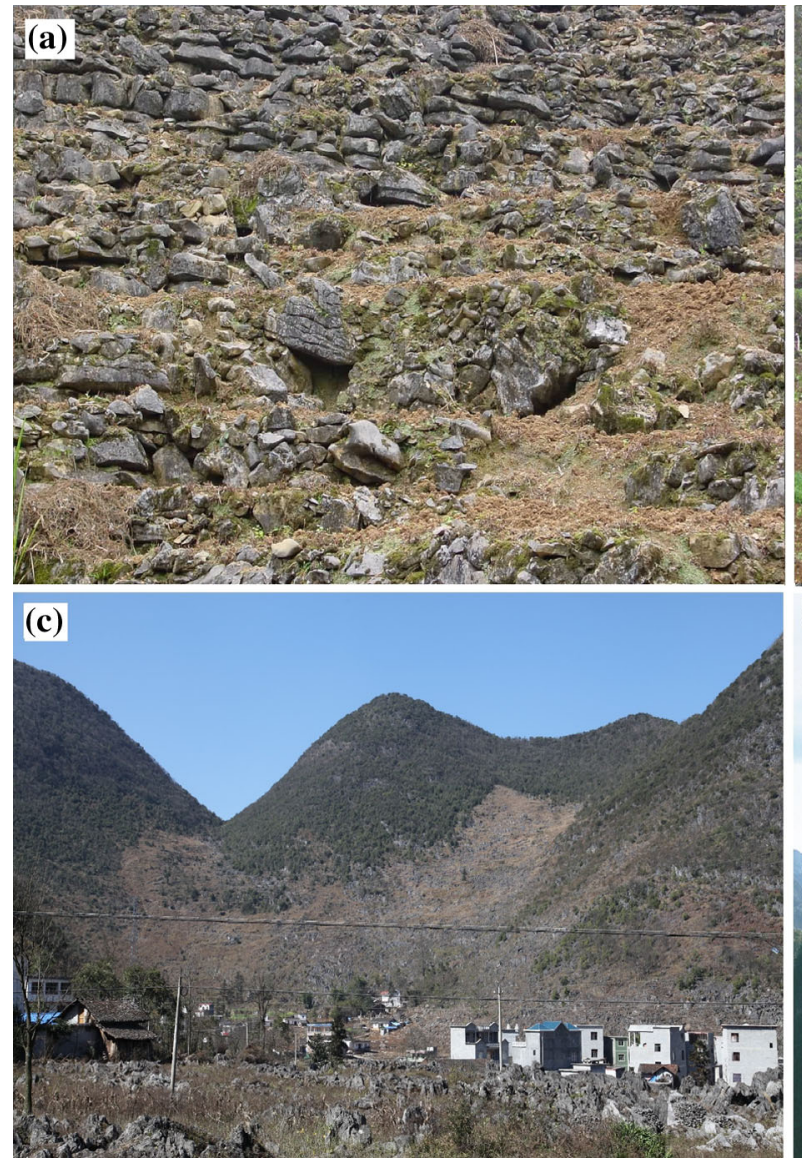

Fig. 2 Images of typical karst landscapes. a A desertified slope in Huanjiang, Guangxi (Imaging date: January 15, 2002), b a typical Maolan (minority) village in Huanjiang, Guangxi (Imaging date: March 25, 2003), $\mathbf{c}$ typical land use pattern in a

In addition to its unique landscapes, the region differs from other karst regions in the world for its high population density and subsequent anthropogenic disturbances. Humans have altered these landscapes significantly; managed properties (e.g., cropland, plantations, constructed) dominate the region. Population density in this region, 217 people $/ \mathrm{km}^{2}$ in 2014 , was 1.6 times the national average (National Development and Reform Commission 2016). In contrast, the region has low urbanization $(43.0 \%$ in 2014 compared to the national average of $54.5 \%$ ). It is also one of the poorest regions in China; rural per capita annual net income was $86.0 \%$ of the national average (National Development and Reform Commission 2016). High population density has led to a need for karst ES (e.g., food and timber) and starting in the middle of twentieth century, KRD has been an

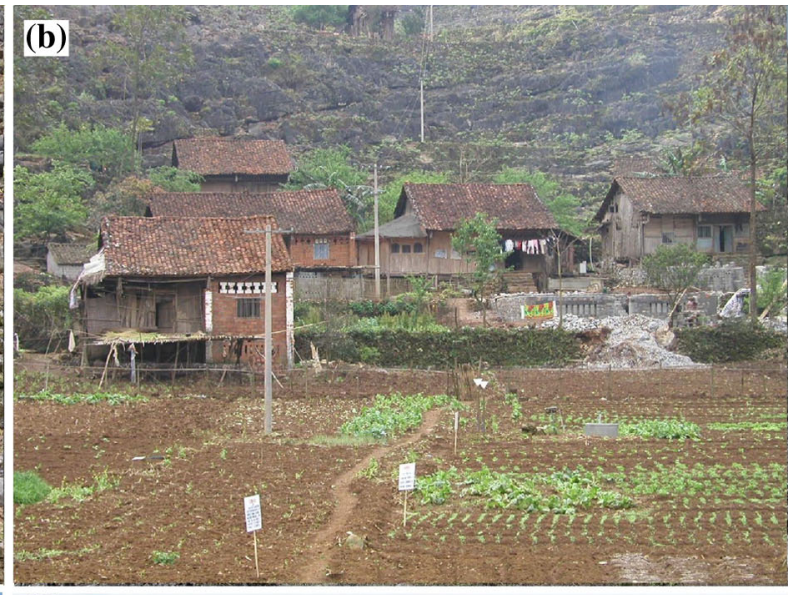

(d)

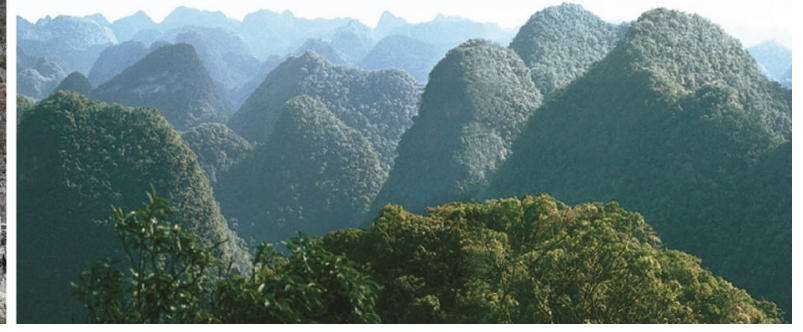

peak-cluster (fengcong) depression (Imaging date: January 24, 2018), d Mulun National Reserve (Guangxi) (Imaging date: November 9, 2007)

environmental problem. Agricultural activities have pushed the degradation of vegetation communities from forests to shrub, grass and bare rock. Agriculture may have increased the number of patches, heterogeneity and decreased landscape stability.

\section{Dynamics of and influences of karst landscapes}

Although there has been complex landscape-patch turnover in this region due to the demand for ES, economic development and ecosystem recovery, some general landscape change patterns remain identifiable. For a typical mountain-basin land system in Guizhou, landscape fragmentation has increased due to settlement expansion and increasing intensity of the road/ highway network between 1963 and 2010 (Li et al. 
2014). However, the number of patches and degree of fragmentation had decreased in the surrounding hill and mountainous regions due to ecological recovery efforts; conversions from cropland and grassland to shrub and forests ( $\mathrm{Li}$ et al. 2014; Qin et al. 2014). In general, the aggregation index has increased, which indicates that larger landscape-patches have formed (e.g., cropland, grassland, shrub land) during this period. Correspondingly, both the spatial extent and severity of KRD has significantly decreased after decades of restoration efforts.

Geological conditions have been suggested as the internal factor that control KRD, soil erosion and forest degradation, and consequently, landscape patterns (Li et al. 2003; Shao et al. 2007). In Guizhou, active KRD normally appears in pure carbonate (especially limestone) dominated regions. Intensity of KRD is less in dolomite-dominated areas ( $\mathrm{Li}$ et al. 2003). There are also correlations between bedrock types and landscape patterns. The percentage and magnitude of sloped cropland (especially on steep slopes) are higher in areas dominated by limestone (Luo et al. 2014). Sloped croplands in dolomite dominated areas are mainly on gentle grades. Average patch sizes in dolomite dominant regions are also larger than those in limestone regions (Tan et al. 2006). In contrast, the degree of degradation has been higher in limestone regions and landscapes are more fragmented in limestone-dominated areas. Differences in chemical components and physical structure cause variation in weathering, soil formation, deposition and loss of dissolution remnants that result in observed landscape patterns.

Other factors, including market-oriented agriculture structure changes, population pressure, ecological engineering, and environmental policies, have been responsible for observed changes (Peng 2006; Zhang et al. 2009c). Such human forces significantly affect landscape patterns. Common disturbances in the region include urbanization, timber and fuel-wood collection, fire (caused primarily by slash and burn agriculture), grazing, quarry-mining, and cultivation (Wang et al. 2006; Zeng et al. 2007). Dominant vegetation community types in this region are shrub, grass and grass-shrub all remnants of a history of anthropogenic disturbance (Zeng et al. 2007; Zhang et al. 2017). Land use intensity has been found to be positively related to economic development. While landscape patterns in basins relatively far away from political centers were stable, basins neighboring political centers were more fragmented due to the land use demand from urban expansion and industrialization (Liu et al. 2017).

Topographic properties and distances to built-up areas are believed to be highly relevant to intensity and extent of human disturbances leading to extant pattern dynamics (e.g., Luo et al. 2011). Landscapes were generally more fragmented at lower elevation where there were stronger and more varied human disturbances (Zhang et al. 2008). Areas of intense human disturbance were found to have lower diversity and the lowest recovery speed. In places of easy access or close to villages, trees may be used for a variety of purposes, thus it is common to see mature trees in inaccessible locations such as cliffs, rock crevices and ridges. Changes to national land management policy affected landscape patterns in this region. The implementation of a household responsibility system in early 1980s initiated the rapid expansion of KRD areas (Chen et al. 2012b); farmers pursued maximum profits from the land without considering environmental consequences. Finally, a variety of domestic uses for external services such as biogas power and electricity for cooking has significantly contributed to the reduction of fuel wood harvesting ( $\mathrm{Li}$ et al. 2013; Qi et al. 2013).

\section{Landscape pattern, hydrological and soil processes}

Landscape dynamics and karst soils

Soils are critical for sustaining ES. However, karst soils are naturally limited in sustaining these functions due to the factors discussed above. Landforms, terrain (slope and aspect), elevation and anthropogenic disturbances determine soil spatial distribution. Better soil (deeper, more nutrients) always develops in areas with gentler slopes (basins, depressions) due to erosion dynamics. Variable elevation, bare rock outcrops and underground conduit systems have also shaped the discontinuity of soil distribution. Large amounts of soil have been lost through high intensity bedrock fractures and underground conduit systems, especially after the removal (fully or partially) of surface vegetation (Wang et al. 2004; Zhang et al. $2007 \mathrm{a}, \mathrm{b}, \mathrm{c})$. Insoluble residues may be carried by water and deposited at lower elevations to form a loose 
sedimentary bed (Wang et al. 2004). Consequently, areas around karst depressions may have a high percentage of rock outcrops.

\section{Soil nutrient and landscape dynamics}

Soil quality generally improves during ecosystem recovery (Wang et al. 2007), however, there are various limiting factors that can slow this process. At early successional stages, soil nutrients, organic matter (SOC), microbes and enzymes are generally low (Wang et al. 2007; Yang et al. 2016). SOC content may recover rapidly following agricultural abandonment (Yang et al. 2016). SOC and total $\mathrm{N}$ were found to be higher in secondary forest, shrub, and low in farmland and commercially forested areas. Ecosystem recovery of grasslands is limited by soil $\mathrm{N}$ as indicated by the foliar $\mathrm{N}: \mathrm{P}$ ratio and several other indicators (Zhang et al. 2015a, b). Consequently, more research should focus on the limiting effects of $\mathrm{N}$ in early successional stages. In contrast, high $\mathrm{NO}_{3}$ concentrations in shrub land, secondary forest and primary forest may imply $\mathrm{N}$ saturation. Phosphorus, instead of $\mathrm{N}$, is the limiting nutrient for secondary succession and ecological restoration in the karst region of southwestern China (Zhang et al. 2015a, b).

When all other factors (e.g., climate, parent materials) are the same, soil properties tend to be controlled by topography and LULC (Zhang et al. 2007b; Zhang et al. 2012b). SOC content, total N, and available N decreased with increasing landuse intensity (Zhang et al. 2006). A rapid decrease of SOC and available $N$ after reclamation was observed after four years of field reclamation trials. Zero-tillage agricultural management and large forage grass root biomass in planting systems were beneficial to alleviate SOC loss (Zhang et al. 2013). Manure application also helped SOC and $\mathrm{K}$ accumulation in the calcareous soil. These results compliment those from space-for-time substitution approaches.

\section{Landscape pattern and soil nutrient/water redistribution}

The spatial distribution of rock outcrops has been found to be critical for the re-distribution of water and soil nutrients and total organic carbon at local scales (Wang et al. 2016a, b, c). A matrix of soil and rock outcrops changes local hydrological process, facilitates soil and nutrient re-distribution and helps to create opportunities for vegetation germination and growth. Soil patches may receive nutrients from direct atmospheric deposition and runoff from surrounding areas. When the rock-to-soil patch area ratio is 7:3 or higher, the contribution of rock outcrops on water and nutrients redistribution likely exceeds that of atmospheric deposition (Zhang et al. 2016). Consequently, a higher proportion of rock outcrops may be linked to higher soil nutrients (Zhang et al. 2006, 2007b). Indeed, higher SOC density has been observed in areas of high rock outcrop ratio (Hu et al. 2018). This variation arises because other hydrologic components (fracture loss, splashing from the rock surface, and rock surface interception) combines with rock runoff to divert SOC and nutrients contained in water inputs. Biological crust may also contribute to the increase of soil fertility (Cao and Yuan 1999; Li et al. 2004b; Hu et al. 2019). Consequently, landscape pattern may be variable even in areas with a high percentage of rock outcrops. Different combinations of soil patches and rock outcrops create various niches for vegetation communities and, in places, the amount of nutrients available from soil patches may be sufficient to support tree growth (Zhang et al. 2016). Given similar vegetation cover, soil water and nutrients are generally higher in soil patches around large rock outcrops because of larger runoff volumes from bare, rock surfaces and shading effects (Hu et al. 2018). Consequently, karst forests may appear in places where the percentage of rock outcrop is high (e.g., Maolan and Mulun karst forests) and tree dominated communities may occupy multiple niches.

Interestingly, in peak-cluster regions (Fig. 2c), one or several families may reside in a depression with cropland concentrically distributed around its center. Above the cropland, at higher elevation, the original vegetation cover persists on steep slopes. The concentric agricultural production model in peak-cluster depressions modifies the epikarst hydrological processes and increases soil erosion. Interflow and soilbedrock interface flow become surface flow in the lower agricultural zone. Soil erosion generally increases due to the lower vegetation cover. On average, soil depth on slopes is $10-20 \mathrm{~cm}$ and in depressions is $40-60 \mathrm{~cm}$. These differences are largely attributed to soil erosion and the accumulation of soil in the depression. The revised epikarst water cycling mechanism decreased the stability of 
agricultural production and increased drought and flood frequency (Zhang et al. 2012a). Correspondingly, human disturbances were reported to cause an inverted pattern of soil nutrients and soil moisture; low in depressions (cropland) and high on slopes where natural vegetation communities persist (Zhang et al. 2006, 2012b). In contrast, the spatial pattern of soil nutrients and moisture in undisturbed karst forests are similar to those in non-karst forests (Liu et al. 2010).

The karst hydrological process and its simulation

\section{Slope hydrological processes and epikarst}

Shallow karst soils are rich in solution features and highly permeable (Fu et al. 2016). The various water leakage structures (e.g., sinkholes, bedrock fractures, caves) facilitate rapid water flow into underground hydrological systems. Consequently, the infiltration rate is generally high; surface runoff from watersheds generally accounted for less than $5 \%$ of the total precipitation and occurred entirely as stormflow (Jiang et al. 2009). Similarly, results from 10 years of runoff monitoring at 13 large runoff plots on a dolomite hillslope indicated that event runoff coefficients were generally smaller than 5\% (Chen et al. 2012a). Differences in epikarst structure, rock formation attributes, land cover and rainfall intensity affect water storage and regulatory functions (Jiang et al. 2001).

Subsurface processes, including soil-bedrock interface flow, epikarst water storage and water leakage, dominate karst slope hydrology. Epikarst overlies the infiltration zone and is between the bedrock and the topsoil. According to results from small plot, field rainfall simulation experiments, more than $70 \%$ of the total rainfall water moved vertically through the shallow soil layer to be redistributed by the epikarst. This occurred as subsurface flow on the soil-epikarst interface, filling depressions on the epikarst surface, deep percolation and held by the epikarst (Fu et al. 2016). An understanding of sub-surface structure and distinctive soil horizon locations is critical to identify the three-dimensional details of flow pathways that control runoff processes in karst regions (Fu et al. 2015). The particular soil-epikarst architecture determines unique near-surface hydrological process $(\mathrm{Fu}$ et al. 2015, 2016). Epikarst is ubiquitous in southwestern China and its formation is primarily affected by geological and climate factors. According to Jiang et al. (2001), there are differences in fissure rates between the epikarst in Liupanshui, Guizhou (30\%) and Longla, Guangxi (60\%). Similarly, the depth of epikarst in more southern, humid and wet Guilin, Guangxi can be as high as $10 \mathrm{~m}$. In contrast, the equivalent depth in Guizhou is approximately $2 \mathrm{~m}$. Epikarst is the main habitat for underground life and one of the main sources of water and nutrient for vegetation growth. Hence, water storage in the epikarst largely determines vegetation community type.

\section{Hydrological process modelling}

Karst aquifers are extremely heterogeneous due to the presence of hierarchical conduit networks in this fractured matrix (Borghi et al. 2016). Karst hydrological models can facilitate our understanding of karst aquifer response to precipitation events at multiple scales and are critical for flood prediction, pollutant transport, nutrient loss and re-distribution and water resource management. Several black-box, conceptual and physical models had been applied to simulate surface, underground runoff dynamics and interactions (Meng and Wang 2010; Chen et al. 2018). However, many of the karst regions lack essential hydrological and auxiliary data for hydrological modeling. It was thus suggested by Chang et al. (2015) that conceptual models are currently the best available for the karst region.

The development of karst specific hydrological models facilitates the examination of interactions between hydrological processes and landscape patterns and can quantify spatial structure of karst aquifers (Meng and Wang 2010; Chen et al. 2018). Distributed models integrate spatial variation in aquifer structure with physical models. Given sufficient data, distributed models can provide reliable hydrological data across extensive areas. However, models run on many hydrological parameters (e.g., precipitation, drainage area, soil properties, vegetation cover, topography, soil moisture content, characteristics of ground water aquifers) and data for the structure of the aquifer system (Chang et al. 2015). Considering the heterogeneity in the karst region, constructing this type of model is challenging (Meng and Wang 2010; Chang et al. 2015). A soil and water assessment tool (SWAT) model, a distributed process-based 
algorithm, promises to simulate water, sedimentation and agricultural chemical yields in predominantly agricultural watersheds (Borah and Bera 2003). It can be applied to examine the impacts of LULC changes on water, soil and chemical yields. Yu et al. (2012) and Tian et al. (2016) successfully applied a SWAT model to estimate water and soil yields in Guizhou at the watershed scale. However, the accuracy varied by season; higher in dry and lower in wet seasons ( $\mathrm{Yu}$ et al. 2012).

\section{Landscape pattern dynamics, water abundance and quality}

Landscape pattern dynamics impact surface runoff, soil erosion and stream water quantity and quality. Relationships among gauged water yield, dissolved inorganic carbon and forest recovery in a karst basin in Guizhou indicated that forest recovery had not significantly affected water yield (Yan et al. 2014). In contrast, a decreasing trend of water and sediment yields corresponded to an increase of grassland and forested land based on model simulation (Tian et al. 2016). Monitoring data from hydrological stations for seven karst catchments also indicated that annual water and sediment discharge had decreased significantly. This change corresponded to an increase in vegetation cover ( $\mathrm{Li}$ et al. 2016b). Consequently, ecological restoration played important roles in a sediment discharge decrease, especially at small scales, while dams typically affect soil water quality at larger scales (e.g., basin wide) (Li et al. 2016b).

Landscape dynamics may also impact water quality. Vegetation cover is critical for avoiding flash flooding and maintaining high water quality (low sediment, pesticide and nutrient load). Sedimentation yield was found to be lower in catchments dominated by pasture and shrub-grass than those in sloped cropland and tea plantations (Jiang et al. 2014b). River (surface) water quality indicators (e.g., total P and ammonia $\mathrm{N}$ ) were influenced by the arrangement of patches and landscape heterogeneity (Cai et al. 2015; Cai et al. 2018).

\section{Soil erosion monitoring and simulation}

Human induced, accelerated soil erosion can be a serious environmental problem in karst regions. The loss of an already thin surface soil layer and soil nutrients lowers land productivity and regional carrying capacity. Monitoring and modelling soil erosion can help conserve soil and water and adapt ecological engineering practices. Soil erosion was reported to be greater between the 1970s and 90s where the average soil erosion modulus were reported to be $256.5 \mathrm{t} /$ $\left(\mathrm{km}^{2}\right.$ year) in Guangxi and $380 \mathrm{t} /\left(\mathrm{km}^{2}\right.$ year $)$ in East Yunnan (Chen 1997). Field measurements conducted in a variety of landforms (e.g., plateau, basin, depression) indicated that surface soil erosion in the region is generally light in intensity $\left(<50 \mathrm{t} /\left(\mathrm{km}^{2}\right.\right.$ year $)$ in comparison to non-karst regions (Chen 1997; Cao et al. 2008). Areas with large values are generally greatly affected by human disturbance (e.g., cropping on slopes). Based on the results of several studies (e.g., Chen 1997; Zhang et al. 2007a, b, c), a national, soil erosion intensity evaluation standard was implemented for the karst region in 2009 (Li and Xiong 2012). This new standard, light soil loss intensity for the karst is between 30 and $100 \mathrm{t} /\left(\mathrm{km}^{2}\right.$ year), which is much less than the national average of $<2500 \mathrm{t} /$ $\left(\mathrm{km}^{2}\right.$ year $)$.

The intensity and distribution of soil erosion may be affected by rainfall intensity, rainfall volume, slope angle, spatial distribution of soil and rock outcrops, soil properties, epikarst structure, connectivity of underground conduit networks, landscape and its management and degree of disturbance (Guerra et al. 2017; Chen et al. 2018). Soil erosion remains relevant to landscape changes at different elevations. Landscape patches with moderate to high soil erosion occur at low to moderate elevation where human disturbances were strongest (Tang et al. 2016). At higher elevation, soil erosion is generally caused by natural forces.

Although surface soil loss is generally light in the karst region, a large amount of soil has been lost through bedrock fractures, sinkholes and conduits connected to ground hydrological systems (Zhang et al. 2007a, b, c). As early as the 1960s, researchers had reported underground soil loss (Chen 1997; Zhou et al. 2009). Since the year 2000, many researchers have examined proofs, mechanisms, and conceptual models of soil underground leakage (Zhang et al. 2007a, b, c; Zhou et al. 2009; Li and Xiong 2012). The ratios of surface and underground soil loss vary according to topological position and epikarst structure (Jiang et al. 2014b). On peaks and slopes, water and soil loss are dominated by vertical leakage through 
sinkholes and bedrock fractures. In depressions, water soil loss is dominated by surface runoff, ending at underground rivers through sinkholes.

Landscape changes, and the intensity of human disturbances affect soil loss rate and extent. Therefore, it is important both to simulate soil erosion and study the response of soil erosion to landscape changes at different scales. In recent years, with the introduction of hydrological and soil erosion models, there have been many applications of karst soil erosion assessment at catchment and larger scales (e.g., $\mathrm{Xu}$ et al. 2008, Feng et al. 2014; Li et al. 2016a). Two model approaches, empirical (e.g., Revised Universal Soil Loss Equation (RUSLE)) and process-based (e.g., Water Erosion Prediction Project (WEPP), the revised Morgan, Morgan and Finney (RMMF), SWAT) have been applied to study soil erosion in karst areas in China with differing degrees of reported success (e.g., $\mathrm{Xu}$ et al. 2008; Feng et al. 2016). However, these models were not designed specifically for karst and may overestimate erosion rates (Feng et al. 2014; Feng et al. 2016).

Heterogeneous karst surfaces and subsurface drainage also generates extremely complex runoff and erosion patterns. Long et al. (2014) evaluated the appropriateness of the WEPP model (Hillslope version) for soil erosion estimation on a slope in Guizhou. Results suggested that, although the model was able to predict generalized soil erosion intensities between different runoff plots and indicate the trend of soil erosion for the study area, the simulation results were 1.5 to 3 times larger than measured data. The investigators concluded that the application of the model must consider underground leakage, percentage of rock outcrop and heterogeneous terrain. As a result, further studies are needed to identify and quantify underground soil loss and anthropogenic factors and incorporate them into the models (Li and Xiong 2012). The introduction of new modelling methods should consider the uniqueness of the aquifer conduit system. Parameters for RUSLE must also be calibrated for the karst (Feng and Zhao 2014; Feng et al. 2016).

Degraded karst ecosystem reconstruction methods and recovery demonstration

In addition to the implementation of general ecological engineering projects (e.g., Green for Grain and environmental migration), nationally sponsored KRD
Fig. 3 Guzhou, Guangxi demonstration site, a typical karstic peak-cluster depression area, in 2004 and 2017. The catchment has an area of $1.87 \mathrm{~km}^{2}$ with an elevation between 375 and $816 \mathrm{~m}$. $\mathbf{a}$ is a SPOT 5 image acquired on May 21, 2004. b is a Gaofen-1 image acquired on May 28, 2017. Both images were shown as standard false color composites (RGB, NIR, Red and Green). c, d are LULC maps extracted from the 2004 and 2017 images respectively. Main LULCs in the depression had changed from cropland to pasture (grassland) and cropland. The majority of the KRD area had disappeared because of recovery efforts spanning more than 10 years

treatment projects have been implemented to study mechanisms of KRD and adaptive ecological restoration technology. For example, an ongoing research project sponsored by the National Key Research and Development Program of China, Technologies for rocky desertification treatment and ESs enhancement in karst peak-cluster depression regions, is being conducted (Wang et al. 2016a, b, c). A series of KRD reconstruction techniques to increase water use efficiency, lessen soil erosion and identify appropriate species for the karst environment were proposed and implemented at several demonstration sites (e.g., Guzhou, Guangxi; Guohua, Guangxi, Huajiang, Guizhou). These were intended to recover the degraded environment and to increase farmers' income (e.g., Jiang et al. 2014b; Wang et al. 2018a, b).

To this end, forage grasses, methods of animal husbandry, herbaceous vine species production and pitaya ecological production approaches were tested at different demonstration sites (e.g., Jiang et al. 2014a, b; Wang et al. 2018a, b). These ecosystem recovery demonstration models attempted to build multifunctional landscapes for both ecological and economic benefits. Practices in several KRD recovery demonstration sites indicated that the implementation of these models, along with forest restoration, can facilitate the recovery of the degraded ecosystem and increase farmers' income. Generally, environmental conditions at demonstration sites improved after decades of recovery (e.g., Figure 3). Based on those practices, management strategies for karst ecosystem of various intensities of disturbances were implemented (Wang et al. 2018).

Karst ES and landscape pattern

Although karst ecosystems provide many ES for society, some provided by karst ecosystems could not even satisfy local demand (e.g., food). This was 

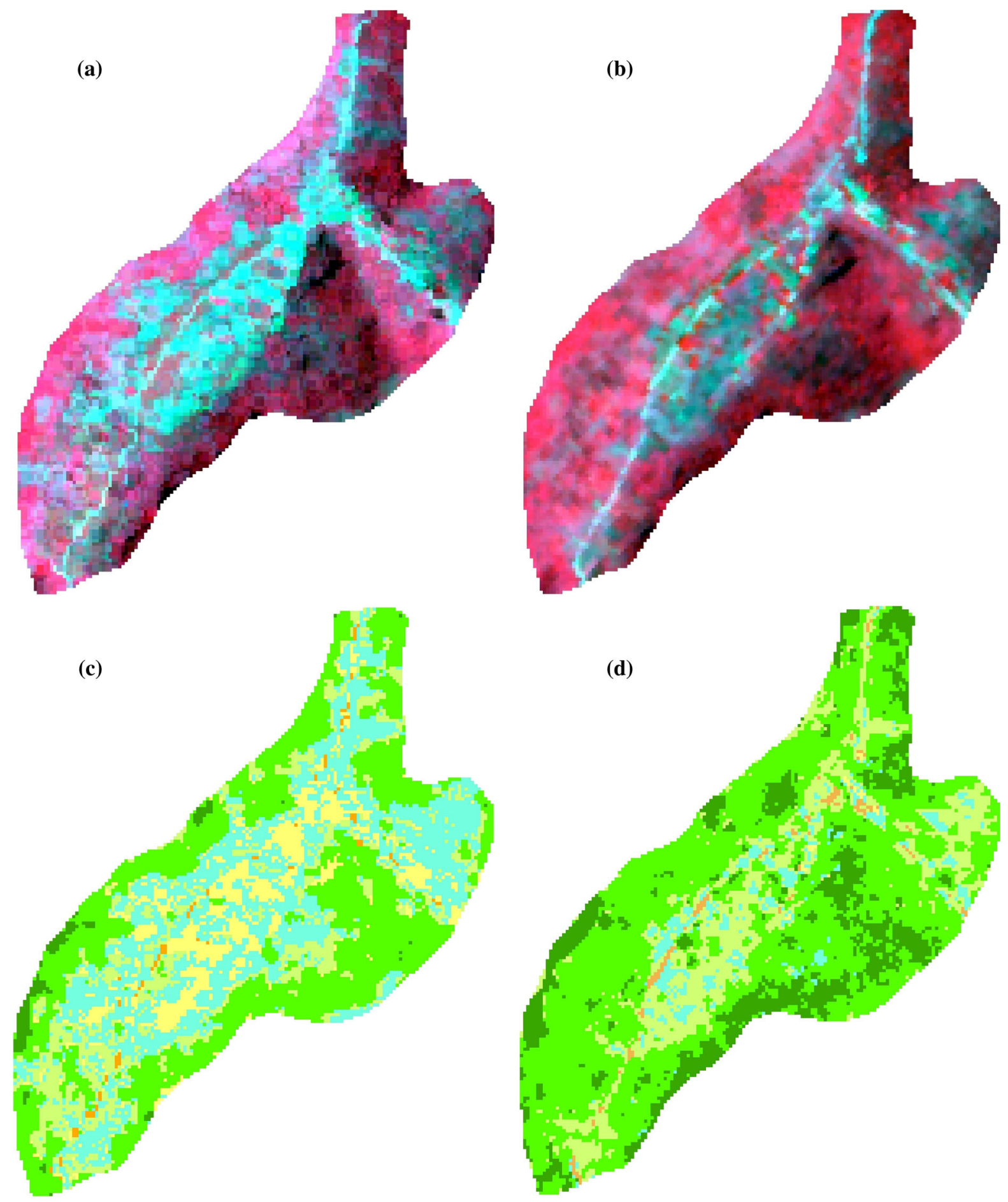

Cropland

Rocky land

Grassland

Shrub land

Forest land

Built-up

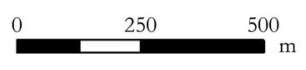


especially true for rugged areas with limited cropland area. The expansion of cropland onto slopes had caused significant environmental degradation in these areas. In contrast, some environmental and resources relevant to karst ES (i.e., water and soil retention, nutrient cycling, and species diversity) are important at local, regional, and national scales. This region is in the upper and middle reaches of Yangtze and Zhu Rivers; two of the largest rivers in China. Environmental conditions in the region affect the environmental status of these provinces' lower reaches. ES assessment may be used to evaluate the recovery of karst ecosystems under the scenario of ecosystem construction; the changes in landscape pattern affects the primary ecological processes, and consequently, ES.

Many comprehensive ES studies have been conducted for KRD ecosystems (e.g., Guo et al. 2013; Zhang et al. 2014; Gao and Xiong 2015) and individual ES (e.g., vegetation carbon sequestration, water regulation, soil conservation; Zhang et al. 2014, 2015a, 2016). More regional assessments of ES dynamics have been completed at karst recovery demonstration sites, watershed, county, prefecture and provincial levels (e.g., Zhang et al. 2009a; Zhou et al. 2011; Tian et al. 2016). Generally, LULC data extracted from satellite images, climatic, statistical and other auxiliary data were used to evaluate ES (e.g. Zhang and Hu 2008; Luo et al. 2014). Most recently, landuse change simulations were conducted to predict ES dynamics (e.g., Zhao 2014; Lu et al. 2017). Most studies indicated that ES in the karst region increased in the twenty-first century and ecological engineering contributed significantly to this increase. Specifically, forests and shrubs contributed more ES than other LULC types (Zhang et al. 2009b; Luo et al. 2014). However, there may be areas having decreased ES. The observed spatial variation may be explained by climate variation, intensity of human disturbances and geological conditions.

\section{Strategies for karst landscape sustainability}

Much progress had been made in the study of karst landscape patterns and ecological processes in southwestern China. This corresponds to the recovery of karst ecosystems at approximately the same time. To achieve the final objective of landscape sustainability, a few strategies can be adopted: (1) developing new agricultural models to enhance karst ES, (2) lowering population pressure through labor export and urbanization, and (3) protecting core karst ecosystem and developing a green (low carbon) economy. These endeavors may contribute to ecological civilization; a process that has been practiced in China since around 2007 (Frazier et al. 2019).

Developing alternative multifunctional agriculture models

Vulnerable karst is not suitable for high intensity agricultural development. However, the high population density in the region necessitates that some agricultural and industrial activities persist. Consequently, sustainable provisioning of ES for residents should be guaranteed. Originally, corn (maize) was the staple crop for both human and hog consumption. However, corn production was shown to change soil physical structure, increase soil erosion and loss of SOC. Hog production in the region also creates a suite of environment problems (e.g., groundwater contamination). The development of a 3 million mu (200,000 ha) walnut plantation in Hechi, Guangxi supported by local government was also unsuccessful; $85 \%$ of trees had no production after 10 years. Plantation construction also caused a moderate degree of KRD. Although the reason for zero production is yet to be explained, the need to develop and implement recovery strategies based on local conditions should be emphasized.

All other agricultural activities in the region should facilitate nitrogen fixation and combat soil erosion. Consequently, recovery design should consider natural conditions and include agriculture, animal husbandry and forestry. The need to reduce the cost of agricultural investment for farmers should be considered in model design. As argued above, the transfer of dominant agriculture activities in the region from corn to forage grass and woody crops may be practical solutions. Forage grass production can maintain a high level of production for at least 10 years with fertilization. Some agricultural models incorporating cropping and husbandry for full use of ecological resources will also be beneficial. Agroforestry has proven to be a practical approach for ecosystem restoration in karst regions. In addition, a vegetation restoration strategy using various plant-function-group assemblages (e.g., 
forest and grass) has been shown to enhance biological crust and improve soil $\mathrm{N}$ properties (Hu et al. 2019).

Alleviating population pressure

Historically, intense anthropogenic disturbances have caused KRD and other environmental problems. Starting in late 1990s, many people from this region migrated to coastal cities and even regional urban centers for work opportunities (labor export). This has lightened the local environmental burden, especially in areas of rugged terrain, and permitted some vegetation community recovery. However, labor export has caused a series of social problems (e.g., family separation, primary education) and slowed urbanization. However, a recent decline in job opportunities in coastal provinces due to the slowdown of Chinese economy has slowed labor exports.

Urbanization in the region has been rapid in past 30 years, accelerating since 2014. However, three provinces dominated by karst landscapes, Guizhou (47.5\%), Yunnan (47.8\%) and Guangxi (50.2\%), are among the five provinces with the lowest urbanization rate in 2018. Their average urbanization (48.5\%) is much lower than the $59.6 \%$ national average. Nevertheless, Guizhou has experienced one of the fastest urbanization growth in the country between 2013 $(37.8 \%)$ and $2018(47.5 \%)$, with an annual increase of $1.3 \%$. Consequently, it is reasonable to expect that with the progress of urbanization and economic development in the region, more and more local village residents will seek to move to and live in cities and nearby towns for higher living standards. Lower population pressure will facilitate karst ecosystem recovery and ES provision.

Protecting karst landscapes and developing a green (low carbon) economy

According to Major Function Orienting Zoning of China (Fan 2015), most karst regions belong to zones restricted for economic or agriculture development. Regional urban centers are exempted from these restrictions, but rural regions are typically not. However, a large portion of this region is an ecological functioning area of national importance. Indeed, the government has identified that ecological ES provisions are among the main contributions from the karst region. Hence, local government should consider changing the development path to balance the demands of economic development and employment against ecological protection and recovery. Carbonintensive infrastructure and industrial development pathways are not the solution for this region.

Influential anthropogenic activities in the karst region make it critical to conserve these spectacular landscapes and ecosystems for their social, scientific, ecological and aesthetic values. One of the solutions has been to create natural reserves and geological parks to demonstrate and preserve their unique properties. Consequently, South China Karst became a UNESCO World Heritage Site in 2007. The site is comprised of 7 clusters: Libo, Shilin, Wulong (Phase I inscription in 2007), Guilin, Shibing, Jinfoshan and Huanjiang (Phase II inscription in 2014). In addition, Maolan, Guizhou and Shilin, Yunan are listed as Biosphere reserves and UNESCO Global Geoparks respectively. The sites are also partly in a World Wildlife Fund Global 200 Eco-region and form a Bird Life International-designated Endemic Bird Area (United States Educational, Scientific and Cultural Organization N.D.).

A green (low carbon) economy, which promotes resource efficiency, green investment, technological innovation and poverty eradiation (Brand 2012), is perhaps one of the most practical paths for the karst region. The specific karst natural and social environment dictates that the region will not be able to host innovation centers in China. However, the beautiful landscapes can contribute significantly to local economic development and poverty alleviation. Fiscal instruments can play a significant role in the transition to a green economy. For example, the practice of experimental forest carbon and ecological compensation projects provided annual revenue of 0.1 billion Yuan (approximately US\$15 million) for Huanjiang County; about $22.2 \%$ of the county's annual revenue. In addition, there has been rapid investment in tourism industry development in the region. Tourist revenue was 1.2 billion Yuan (US\$0.18 billion) for Huanjiang County, Guangxi in 2018, an annual increase of 38.2\% over 2017. In contrast, the gross domestic production of secondary industry of the county was 1.9 billion Yuan (US\$ 0.29 billion). These diverse industries provide alternative sources of income/revenue and employment opportunities for residents and governments. The benefits of ecosystem preservation and 
protection will further motivate local government and residents' efforts for environmental protection.

Innovative management of non-commercial forest can also contribute to local economic development. Many forests in the region belong to non-commercial stands; it is illegal to harvest timber and other forest products for profit. Nevertheless, villagers need to diversify their incomes to sustain their standard of living. Consequently, the management of ecologically important, non-commercial forest is critical for local and regional ecological security. Several measures have been taken to deal with this. Governments at different levels have established compensation funds (e.g., 15 yuan/mu for village-owned, non-commercial forests from the federal government). In addition, pledges have been offered to advance expected proceeds for non-commercial forests for a maximum of 5 years to provide development funds for ecotourism, animal husbandry and under-forest economies for villagers. This policy gives residents the opportunity to both protect the non-commercial forest and increase family income.

Improved karst landscape planning and design for regional sustainability

Regional sustainability requires planning and design to 'optimize' the spatial pattern of diverse landscape types. Two initiatives, "building beautiful countrysides" and "countryside vitalization", were begun by the federal government recently under the context of "building a beautiful China by 2035" (Xi 2017). Large financial investments have and will continue to be made in the region to improve rural facilities, economic development and the environment. After the completion of these initiatives, it is likely that the landscape of this region will be significantly modified. Appropriate regional economic, environmental, transportation and settlement planning are critical compliments to the investments to assure success.

During the process of developing master plans and specific designs, four ecological principles should be followed. First, planning and designs should integrate elements of multifunctional landscapes. Multifunctional landscapes help integrate ecosystem services and human well-being. They can support livelihoods, protect species, allow karst ecosystems to function sustainably and provide recreational needs (O'Farrell and Anderson 2010; Wu 2013). Although the multifunctional principle was applied in several regional demonstration sites (as shown in a previous section), more work is needed to make it a compulsory component for future planning and landscape design.

Second, it is critical that regional diversity be maintained during future development. Increasing heterogeneity may improve ES and ecosystem resilience. Specifically, cultural legacies from the large number of residents from minority nationalities (e.g., clothing, tradition, housing styles) enriches the national cultural landscape.

Third, collaborative and participatory approaches that include stakeholder involvement are essential for sustainable landscape solutions (Opdam et al. 2018). Adaptive ecological design, that considers relationships between landscape pattern and ecological processes, encourages public participation, and balances heterogeneity and stability, should be practiced for landscape design in the karst region (Yu et al. 2009).

Finally, landscape design should be included in land consolidation initiatives (LCI). LCI, a process of applying biological and engineering techniques to reorganize and optimize land resources (e.g., cropland, wetland, facilities and villages) (Luo and Zhang 2002), have been practiced in China for about 20 years. LCI includes landscape planning and design of farmland patches, irrigation and drainage engineering, road engineering and biodiversity projection engineering (Wang et al. 2011). The fragmented landscape makes it necessary for LCI to be an ongoing process to optimize LULC and to lower environmental impacts from agricultural and other land uses.

\section{Ongoing research supporting policy for sustainable karst landscapes}

Research had played a key role in karst restoration efforts. The abandonment of terracing for ecosystem recovery in the karst region was based on years of scientific research. This work indicated that terracing was not an efficient approach for soil erosion control; the main pathway of water and soil loss are through sinkholes, fissures and underground conduit systems. As a result, terracing in karst is not as effective as in the Loess Plateau or hilly, red-soil regions. Other examples include the reduction of corn cultivation, KRD treatment models and the establishment of an evaluation standard for karst soil erosion intensity. 
Further research is needed to model karst hydrological and soil processes to improve our understanding of landscape patterns and processes and to conduct comprehensive karst ES assessment (Frazier et al. 2019). Research will support an ongoing KRD treatment project (stage II 2016-2025); the largest ecological engineering project in China after the Northern China (three-north) shelter forest program. This work will generally enrich landscape sustainability science.

Improved landscape change modelling

for hydrological and soil processes studies and landscape design

Landscape dynamic simulations are critical for studying future landscape structure and hydrological processes, ES assessment and analyzing the causes and consequences of potential landscape dynamics in response to socio-economic and natural forces. There have been various efforts to use data extracted from satellite images to simulate landscape change. For example, Conversion of Land Use and its Effects at Small region extent (CLUE-S), Markov and CAMARKOV models have been used to simulate future LULC changes (e.g., Zhao 2014; Ma et al. 2015; Lu et al. 2017). Results from these simulations are useful for projecting future, spatially-explicit and scenariobased landscape change. However, DINAMICA EGO, a model using a similar empirical approach based on past LULC, remains untested. This package has more flexibility and the tools to develop customized models than previously possible (Mas et al. 2014). A cellular automation-based future land use simulation (FLUS) model proposed in a Chinese-landscape context may also be tested for the region. This model includes topdown and bottom-up models to reflect the impact of macro-scale demands, political planning and climatic change on LULC (Liu et al. 2017). Finally, processbased approaches (e.g., sector-based economic models, spatial disaggregated economic models and agentbased approaches) may provide more realistic representations of landscape change by incorporating supply and demand on landuse decisions and the actions of land-change actors (Geographical Sciences Committee 2014). Although it is challenging to incorporate socio-economic factors in models due to barriers in collecting socio-economic data (e.g., household surveys) and to integrate these with biophysical factors, it remains worthwhile to test this group of models in the karst and contribute to the development of landscape science.

Improved landscape pattern modelling will also improve how landscape dynamic loading for critical interacting factors is quantified. Many interacting factors contribute to vegetation recovery. Canonical correspondence analysis, correlation and regression and principal component analyses (e.g., Zhang et al. 2008b; Ma et al. 2015; Wang 2016a, b, c) were applied to examine the relationships among landscape dynamics and key factors. However, it is challenging to identify the magnitude of impacts of individual factors because of intricate, among-factor interactions. Consequently, the question of the degree to which ecological engineering has contributed to the recovery remains open. As a step forward, residual analysis has been conducted to separate the effects of climate variation from other impacting factors on ES dynamics (e.g., Zhang et al. 2016). A dynamic vegetation model (LPJ-GUESS) was used to simulate Leaf Area Index and aboveground biomass carbon dynamics without conservation practices with results compared to reference satellite data (Tong et al. 2018). It was found that conservation practices contributed significantly to increasing $\mathrm{ABC}$ during the period of project implementation. Finally, it was found that over 0.9 million $\mathrm{km}^{2}$ of land in the region $(75.3 \%$ of the land area) had, on-average, a $4 \%$ increase in biomass (Brandt et al. 2018). Results from these studies appear to suggest that ecological engineering has contributed significantly to ecosystem recovery over much of the karst region. These achievements have mitigated GCC at the regional scale. However, decreasing population pressure during the same period was not considered in these studies; many farmers migrated to cities for better job opportunities. This gap suggests that effort is still needed to clearly identify and understand the key factors contributing to ecosystem recovery at different scales.

Advancing 3-dimensional karst hydrological and soil process knowledge

A critical advance would be to apply new technology to quantify subsurface drainage. More work should be done to identify ground features, including the structure and role of epikarst on hydrological processes. It may be feasible to infer subsurface conditions based on landscape patterns (Gao et al. 2018). Imaging the 
structure and hydraulic properties will help understand how water moves through the subsurface. Advances in geophysical instrumentation makes possible the integration of geophysical features with hydrological, process-based watershed data (Robinson et al. 2008). For example, airborne electromagnetic and transient electromagnetic methods can be applied to collect information from the sub-watershed to basin scales. Ground-based EMI and Ground Penetrating Radar can be used to map soil texture, catchment-scale flow pathways and to collect line transect data. These can aid in identifying the depth to impermeable layers (Robinson et al. 2008). Results from the integration may revolutionize hydrogeological interpretation and improve our understanding of dynamic hydrological processes. Together, these techniques can facilitate the construction of a seamless, subsurface image.

Spatially distributed hydrological modelling of the karst should be further investigated (Meng and Wang 2010; Chen et al. 2018). Much work needs to be done to parameterize and improve models for the karst region; e.g., below-ground processes that may be more important than surface processes. Models could address problems related to physical features of hydrological behavior and nonlinearity of karst aquifers, analyze the characteristics and regional differentiation of all storage forms and develop methods and distributed models to define quantitatively the distribution of subsurface drainage (Meng and Wang 2010; Chang et al. 2015). Interactions between landscape heterogeneity and hydrological processes should also be further explored (Gao et al. 2018). Other foci should include establishing a database of optimal parameters and incorporating the eco-hydrologic response and water resource assessment in hydrological models (Chang et al. 2015). Such a database will benefit the development of hydrological models in areas lacking monitoring data and permit the comparison of competing models. Finally, more effort should be invested in landscape-based modelling for ungauged basins (Gao et al. 2018).

\section{Comprehensive and karst-specific ES assessments}

Many regional ES studies have adopted the unit valuebased approach proposed by Costanza et al. (1997) (Chinese version by Xie et al. 2006; e.g., Xiong et al. 2008; Zhang and $\mathrm{Hu}$ 2008). These methods are straightforward to implement because the assessment is largely based on unit values. However, there may be large variation in estimates among studies because of variation in regions and ES classification systems (Gao and Xiong 2015). Estimate differences among studies have been indeed quite large (Zhou et al. 2011; Gao and Xiong 2015). Considering the uniqueness of the karst ecosystem, there is a need to establish an assessment system specifically for karst (Zhang et al. 2009b; Zhang et al. 2011). In addition, currently existing ES models (e.g., integrated valuation of ecosystem services and trade-offs-InVest, artificial intelligence for ecosystem services-ARIES, ecological asset inventory and management-EcoAIM, service path attribution networks-SPANs (Wu 2013; Ochoa and Urbina-Cardona 2017) should be tested and revised for the karst region.

ES assessment should be expanded to include landscape services. Landscape pattern and dynamics can alter the ability of ecosystem to provide services. Consequently, landscape services have been proposed to mitigate the impacts of landscape pattern (metrics) on ES (Duarte et al. 2018). While the proportion of natural areas and no-crop areas have been shown to affect disease control and pest responses, landscape heterogeneity also affects aesthetic value and water quality (Duarte et al. 2018). Although there had been some studies examining the relationship between landscape metrics and ES (e.g., Zhang et al. 2010a, b; Cai et al. 2015, 2018), further work is needed to identify how landscape structure impacts ES in karst. GCC, and the coupling effects of natural and anthropogenic impacts, may also be incorporated into assessments.

Better methods to identify trade-offs at all scales should continue to be investigated (Seppelt et al. 2013); maximization of one or more services may negatively impact other services provided. Sustainable land use requires an analysis of trade-offs to reconcile requirements and demands (Seppelt et al. 2013). The relationships among ESs are complex, non-linear and may vary at different scales. Researchers have applied correlation analyses to explore ES trade-offs and the synergic relationships between several ESs at the watershed scale (e.g., Tian et al. 2016). The combination of optimization algorithms with scenario analysis may provide better alternatives for landscape management (Seppelt et al. 2013).

Finally, there needs to be more study of cultural ES (except tourism). Such work is lacking in the karst 
landscapes specifically, and generally across China (Jiang 2017). Although it is challenging to assess cultural ES, approaches have been proposed for landscape aesthetics, perception and local identity (Jiang 2017). Subcategories of cultural ES, for example, include aesthetic, spiritual and religious, educational and cultural heritage values, a sense of place, and cultural diversity. These are key elements that impact policies at regional and national scales (Milcu et al. 2013) and should be examined. This research is critical to the success of better ecological planning for this vast, rural region.

Open Access This article is distributed under the terms of the Creative Commons Attribution 4.0 International License (http:// creativecommons.org/licenses/by/4.0/), which permits unrestricted use, distribution, and reproduction in any medium, provided you give appropriate credit to the original author(s) and the source, provide a link to the Creative Commons license, and indicate if changes were made.FundFunding This research was supported by two grants awarded to Kelin Wang (Strategic Priority Research Program of Chinese Academy of Sciences-XDA23060103 and the National Key Research and Development Program of China2016YFC0502400).

\section{References}

Borah DK, Bera M (2003) Watershed-scale hydrologic and nonpoint-source pollution models: review of mathematical bases. Transact ASAE 46:1553-1566

Borghi A, Renard P, Cornaton F (2016) Can one identify karst conduit networks geometry and properties from hydraulic and tracer test data. Adv Water Resour 90:99-115

Brand U (2012) Green economy-the next oxymoron? No lessons learned from failures of implementing sustainable development. GAIA 21:28-32

Brandt M, Yue Y, Wigneron JP, Tong X, Tian F, Jepsen MR, Xiao X, Verger A, Mialon A, Al-Yaari A, Wang K, Fensholt R (2018) Satellite-observed major greening and biomass increase in South China Karst during recent decade. Earth's Future 6:1017-1028

Cai H, He Z, An Y, Zhang C, Deng H (2015) Relationships between land use and water quality in Chishui River Basin based on RS and GIS. Resour EnvironYangtze Basin 24:286-291 (in Chinese with English abstract)

Cai H, Lin G, Kang W (2018) The effects of sloping landscape features on water quality in the upper and middle reaches of the Chishui River Watershed. Geogr Res 37:704-716 (in Chinese with English abstract)

Cao J, Yuan D (1999) Relationship between water holding of carbonate rock and saxicolous algae, lichen and moss and its ecological significance. Geochimica 28:248-256 (in Chinese with English Abstract)
Cao J, Yuan D, Pan G (2003) Some soil features in karst ecosystem. Adv Earth Sci 18:37-44 (in Chinese with English abstract)

Cao J, Yan D, Zhang C, Jiang Z (2004) Karst ecosystem constrained by geological conditions in southwest China. Earth Environ 32:1-8 (in Chinese with English abstract)

Cao J, Jiang Z, Yang D, Pei J, Yang H, Luo W (2008) Grading of soil erosion intensity in Southwest karst area of China. Sci Soil Water Conserv 6:1-7 (in Chinese with English abstract)

Chang Y, Wu J, Jiang G (2015) Modeling the hydrological behavior of a karst spring using a nonlinear reservoir-pipe model. Hydrogeol J 23:901-914

Chen X (1997) Soil erosion in karst mountainous region. J Soil Erosion Water Conserv 3:31-36 (in Chinese)

Chen H, Liu J, Zhang W, Wang K (2012a) Soil hydraulic properties on the steep karst hillslopes in northwest Guangxi, China. Environ Earth Sci 66:371-379

Chen H, Yang J, Fu W, He F, Wang K (2012b) Characteristics of slope runoff and sediment yield on karst hill-slope with different land-use types in northwest Guangxi. Trans Chin Soc Agric Eng 28:121-126 (in Chinese with English abstract)

Chen H, Li C, Fu Z, Lian J, Wang K (2018) Characteristics of soil erosion in the karst regions of Southwest China: research advance and prospective. J Soil Water Conserv 32:10-16 (in Chinese with English abstract)

Costanza R, d'Arge R, de Groot R, Farber S, Grasso M, Hannon B, Limburg K, Naeem S, O’Neill RV, Paruelo J, Raskin RG, Sutton P, van den Belt M (1997) The value of the world's ecosystem services and natural capital. Nature 387:253-260

Duarte GT, Santos PM, Cornelissen TG, Ribeiro MC, Paglia AP (2018) The effects of landscape pattern on ecosystem services: meta-analysis of landscape service. Landscape Ecol 33:1247-1257

Fan J (2015) Draft of major function oriented zoning of China. Acta Geogr Sin 70:186-201 (in Chinese with English abstract)

Fan F, Wang K, Xiong Y, Xuan Y, Zhang W, Yue Y (2011) Assessment and spatial distribution ofwater and soil loss in karst regions in Southwest China. Acta Ecologica Sinica 31:6353-6362 (inChinese with English abstract)

Feng T, Chen H, Wang K, Zhang W, Qi X (2014) Modelling soil erosion using a spatially distributed model in a karst catchment of northwest Guangxi, China. Earth Surf Proc Land 39:2121-2130

Feng T, Chen H, Polyakov V, Wang K, Zhang X, Zhang W (2016) Soil erosion rates in two karst peak-cluster depression basins of northwest Guangxi, China: comparison of RUSLE model with radiocesium record. Geomorphology 253:217-224

Ford D, Williams PD (2007) Karst hydrogeology and geomorphology. Wiley, New York

Frazier AE, Bryan BA, Buyantuev A, Chen L, Echeverria C, Jia P, Liu M, Li Q, Ouyang Z, Wu J, Xiang W, Yang J, Yang L, Zhang S (2019) Ecological civilization: perspectives from landscape ecology and landscape sustainability science. Landscape Ecol 34:1-8

Fu Z, Chen H, Zhang W, Xu Q, Wang S, Wang K (2015) Subsurface flow in a soil-mantled subtropical dolomite 
karst slope: a field rainfall simulation study. Geomorphology 250:1-14

Fu Z, Chen H, Xu Q, Jia J, Wang S, Wang K (2016) Role of epikarst in near-surface hydrological processes in a soil mantled subtropical dolomite karst slope: implications of field rainfall simulation experiments. Hydrol Process 30:795-811

Gao J, Xiong K (2015) Ecosystem service value responses to ecological control in karst region: a case study of Huajiang Gorge Rocky Desertification Control Demonstration Area, Guizhou. Chin J Eco-Agric 23:775-784 (in Chinese with English abstract)

Gao H, Sabo JL, Chen X, Liu Z, Yang Z, Ren Z, Liu M (2018) Landscape heterogeneity and hydrological processes: a review of landscape-based hydrological models. Landscape Ecol 33:1461-1480

Geographical Sciences Committee (2014) Advancing land change modeling: opportunities and research requirements. National Academies Press, Washington

Guerra AJT, Fullen MA, Jorge MCO, Bezerra JR, Shokr MS (2017) Slope processes, mass movement and soil erosion: a review. Pedosphere 27:27-41

Guo H, Wang Y, Lu Q, Zhou J, Wei Q (2013) Assessing karst ecosystem service: a case study in Jingsha, Guizhou. Carsologica Sinica 32:211-217 (in Chinese with English abstract)

Hu P, Liu S, Ye Y, Zhang W, Wang K, Su Y (2018) Effects of environmental factors on soil organic carbon under natural or managed vegetation restoration. Land Degrad Dev 29:387-397

Hu P, Zhang W, Xiao L, Yang R, Xiao D, Zhang J, Wang W, Chen H, Wang K (2019) Moss-dominated biological soil crust modulate soil nitrogen following vegetation restoration in a subtropical karst region. Geoderma 252:70-79

Jiang G (1995) A preliminary report on the biodiversity in the Mulun Karst Forest. Chin Biodivers 3:91-94 (in Chinese with English abstract)

Jiang W (2017) Ecosystem services research in China: a critical review. Ecosyst Serv 26:10-16

Jiang Z, Wang R, Pei J, He S (2001) Epikarst zone in South China and its regulation function to karst water.Carsologica Sinica 20:106-110 (in Chinese with English abstract)

Jiang G, Chen K, Yu S, Peng W (2009) Separating karst slope runoff in peak cluster area. J China Hydrol 29:14-19 (in Chinese with English abstract)

Jiang Z, Lian Y, Qin X (2014a) Rocky desertification in Southwest China: impacts, causes, and restoration. Earth Sci Rev 132:1-12

Jiang Z, Luo Q, Deng Y, Cao J, Qin X, Li Y, Yang Q (2014b) The leakage of water and soil in the karst peak cluster depression and its prevention and treatment. Acta Geosci Sin 35:535-542 (in Chinese with English abstract)

Li J, Xiong K (2012) Research on water and soil loss in China karst area: status, issues and trend. Chin J Soil Sci 43:1001-1007 (in Chinese with English abstract)

Li R, Wang S, Zhou D, Zhang D, Li F, Zhou Z, Xiong K (2003) The correlation between rock desertification and lithology in karst area in Guizhou. Acta Geogr Sin 58:314-320 (in Chinese with English abstract)
Li Y, Wang S, Li R (2004a) Some soil features of karst ecosystem. Ecol Environ 13:434-438 (in Chinese with English abstract)

Li Y, Wang S, Xie D, Shao J (2004b) Landscape ecological characteristics and ecological construction of karst mountain areas in southwest China. Ecol Environ 13:702-706 (in Chinese with English abstract)

Li Y, Xie D, Wei C (2004c) Correlation between rock desertification and variations of soil and surface vegetation in Karst eco-system. Acta Pedol Sin 41:196-202 (in Chinese with English abstract)

Li J, Tu J, Tong L, Guo Z (2013) Evolution and impacting factors rocky desertification in Guizhou: 1988-2008. Remote Sens Land Resour 25:133-137

Li Y, Yao Y, Xie J, Wang F, Bai X (2014) Spatial-temporal evolution of land use and landscape pattern of the mountain-basin system in Guizhou Province. Acta Ecol Sin 34:3257-3265 (in Chinese with English abstract)

Li Y, Bai X, Zhou Y, Qin L, Tian X, Tian Y, Li P (2016a) Spatial-temporal evolution of soil erosion in a typical mountainous karst basin in SW China, based on GIS and RUSLE. Arab J Sci Eng 41:209-221

Li Z, Xu X, Yu B, Xu C, Liu M, Wang K (2016b) Quantifying the impacts of climate and human activities on water and sediment discharge in a karst region of southwest China. J Hydrol 542:836-849

Liu L, Zeng F, Song T, Peng W, Wang K, Qin W, Tan W (2010) Spatial heterogeneity of soil nutrients in Mulun National Nature Reserve. Chin J Appl Ecol 21:1667-1693 (in Chinese with English abstract)

Liu X, Liang X, Li X, Xu X, Ou J, Chen Y, Li S, Wang S, Pei F (2017) A future land use simulation model (FLUS) for simulating multiple land use scenarios by coupling human and natural effects. Landsc Urban Plan 168:94-116

Long M, Wu K, Xiong K (2014) Assessment of the applicability of the WEPP model (Hillslope Version) for soil erosion in Karst rock desertification area, Guizhou Province. Carsol Sin 33:201 (in Chinese with English abstract)

Lu G, Niao C, Xu Y, Zhang T, Li H (2017) Dynamic simulation of future ecosystem service value in Puding County, Guizhou based on CA-Markov model. J Nanjing For Univ (Natural Sciences Edition) 41:49-56 (in Chinese with English abstract)

Luo M, Zhang H (2002) Land consolidation and its ecological and environmental impacts. Resour Sci 24:60-63 (in Chinese with English abstract)

Luo G, Li Y, Wang S, Cheng A, Dan W (2011) Comparison of ecological significance of landscapediversity changes in karst mountains: a case study of 4 typical karst area in Guizhou Province. Acta Ecologica Sinica 31:3882-3889 (in Chinese with English abstract)

Luo G, Wang S, Li Y, Bai X (2014) Spatio-temporal dynamics and ecological service function assessment of slope farmland in Karst areas of Guizhou province, China. Trans Chin Soc Agric Eng 30:233-243 (in Chinese with English abstract)

Ma S, Zhang Y, An Y (2015) Spatial evolution simulation of karst rocky desertification based on logistic-CA-Markov models. Carsol Sin 34:591-598 (in Chinese with English abstract) 
Mas JF, Kolb M, Paegelow M, Olmedo MTC, Houet T (2014) Inductive pattern-based land use/cover change models: a comparison of four software packages. Environ Model Softw 51:94-111

Meng H, Wang L (2010) Advance in karst hydrological models. Progr Geogr 29:1311-1318 (in Chinese with English abstract)

Milcu AI, Hanspach J, Abson D, Fischer J (2013) Cultural ecosystem services: a literature review and prospects for future research. Ecol Soc 18(3):44

National Development and Reform Commission. (2016) Construction plan for comprehensive recovery project for karst regions (2016-2020). (http://www.sdpc.gov.cn/zcfb/ zcfbghwb/201604/W020160422408397731645.pdf). Accessed 30 Dec 2016

Nie Y, Chen H, Wang K, Ding Y (2014) Seasonal variations in leaf $\delta 13 \mathrm{C}$ values: implications for different water use strategies among species growing on continuous dolomite outcrops in subtropical China. Acta Physiol Plant 36(10):2571-2579

O'Farrell PJ, Anderson PM (2010) Sustainable multifunctional landscapes: a review to implementation. Curr Opin Environ Sustain 2:59-65

Ochoa V, Urbina-Cardona N (2017) Tools for spatially modeling ecosystem services: publication trends, conceptual reflections and future challenges. Ecosyst Serv 26:155-169

Opdam P, Luque S, Nassauer J, Verburg PH, Wu J (2018) How can landscape ecology contribute to sustainability science? Landscape Ecol 33:1-7

Peng J (2006) Land use/cover change in ecologically fragile karst areas-A case study in Maotiaohe River Basin. PhD thesis: Beijing, Beijing University, p 158 (in Chinese with English abstract)

Qi X, Wang K, Zhang C (2013) Effectiveness of ecological restoration projects in a karst region of southwest China assessed using vegetation succession mapping. Ecol Eng $54: 245-253$

Qin L, Bai X, Wang S, Zhou D, Luo G, Zhang S, Li P, Li Y (2014) Landscape pattern evolution of typical karst plateau in Puding, Guizhou during last 40 years. Chin J Ecol 33:3349-3357 (in Chinese with English abstract)

Robinson DA, Binley A, Crook N, Day-Lewis FD, Ferre TPA, Grauch VJS, Knight R, Knoll M, Lakshmi V, Miller R, Nyquist J, Pellerin L, Singha K, Slater L (2008) Advancing process-based watershed hydrological research using nearsurface geophysics: a vision for, and review of, electrical and magnetic geophysical methods. Hydrol Process 22:3604-3635

Seppelt R, Lautenbach S, Volk M (2013) Identifying trade-offs between ecosystem services, land use, and biodiversity: a plea for combining scenario analysis and optimization on different spatial scales. Curr Opin Environ Sustain 5:458-463

Shao J, Li Y, Wang S, Wei C, Xie D (2007) The distribution and diversity of landscape patches in different lithology-landform types in karst mountainous areas. J Nat Resour 22:478-485 (in Chinese with English abstract)

Song T, Peng W, Du H, Wang K, Zeng F (2014) Occurrence, spatial-temporal dynamics and regulation strategies of karst rocky desertification in southwest China. Acta Ecol Sin 34:5328-5341 (in Chinese with English abstract)
Tan Q. (2006) Karst rocky desertification pattern variations at different scales and its impacting factors. Ph.D. thesis: Guiyang, Institute of Geochemistry, Chinese Academy of Sciences p 135 (in Chinese with English abstract)

Tang R, Wang X, Shu T, Zhao S (2016) Analysis of vertical landscape patter of soil erosion in karst mountainous area. J Mount Agric Biol 36:30-35 (in Chinese with English abstract)

Tian Y, Wang S, Bai X, Luo G, Xu Y (2016) Trade-offs among ecosystem services in a typical karst watershed, SW China. Sci Total Environ 566-567:1297-1308

Tong X, Brandt M, Yue Y, Horion S, Wang K, Keersmaecker WD, Tian F, Schurgers G, Xiao X, Luo Y, Chen C, Myneni R, Shi Z, Chen H, Fensholt R (2018) Increased vegetation growth and carbon stock in China karst via ecological engineering. Nature Sustainability 1:44-50

United States Educational, Scientific and Cultural Organization. South China karst. http://whc.unesco.org/en/list/1248/. Accessed 30 July 2018

Wang S, Li R, Sun C, Zhang D, Li F, Zhou D, Xiong K, Zhou Z (2004) How types of carbonate rock assemblages constrain the distribution of karst rocky desertified land in Guizhou Province, PR China: phenomena and mechanisms. Land Degrad Dev 15:123-131

Wang J, Lin C, He T (2006) Human activities and the prevention and control of rocky desertification in Guizhou karst mountainous region. Res Soil Water Conserv 13:276-279 (in Chinese with English Abstract)

Wang Y, Wang K, Zou D, Li L, Chen Z (2007) Effects of vegetation succession on soil quality in karst region of Guangxi, China. J Soil Water Conserv 21:130-134 (in Chinese with English Abstract)

Wang J, Li Z, Bai Z, Guo Y, Qiu Z, Wang G (2011) Landscape ecological planning and design of land consolidation in karst area: a case study of land consolidation project in Libo, Guizhou. Progr Geogr 30:906-911 (in Chinese with English Abstract)

Wang L, An Y, Xu J, Ma S, An H (2016a) Characteristics of change of land cover and landscape pattern in different karst regions: a case study in Anshun, Guizhou. J Guizhou Normal Univ 34:23-31 (in Chinese with English Abstract)

Wang D, Shen Y, Li Y, Huang J (2016b) Rock outcrops redistribute organic carbon and nutrients to nearby soil patches in three karst ecosystems in SW China. PLoS ONE 11:e0160773

Wang K, Yue Y, Ma Z, Lei T, Li D, Song T (2016c) Research and demonstration on technologies for rocky desertification treatment and ecosystem services enhancement in karst peak-cluster depression regions. Acta Ecol Sin 36:7098-7102 (in Chinese with English Abstract)

Wang K, Chen H, Yue Y. (2018a) Progress of landscape ecological studies in the karst regions. Ecological Society of China (Editor) Report on Advances in Landscape Ecology (2016-2017) pp 117-124 (in Chinese)

Wang K, Chen H, Zeng F, Yue Y, Zhang W, Fu Z (2018b) Ecological research supports eco-environmental management and poverty alleviation in karst region of Southwest China. Bull Chin Acad Sci 33:1187-1196 (in Chinese with English Abstract) 
Wu J (2013) Landscape sustainability science: ecosystem services and human well-being in changing landscapes. Landscape Ecol 28:999-1023

Xi J. (2017) Secure a decisive victory in building a moderately prosperous society in all respects and strive for the great success of socialism with Chinese characteristics for a new Era. http://english.jschina.com.cn/special/36190/201711/ t20171105_4806508.shtml. Accessed 26 Aug 2018

Xie G, Xiao Y, Lu C (2006) Study on ecosystem services: progress, limitation and basic paradigm. J Plant Ecol 30:191-199 (in Chinese with English abstract)

Xiong Y, Xie G, Zeng G, Wang K, Yang C (2008) Influence of land use change on ecosystem service value-A case study in Huangjiang, Guangxi. China Environ Sci 28:201-214 (in Chinese with English abstract)

Xu Y, Shao X, Kong X, Peng J, Cai Y (2008) Adapting the RUSLE and GIS to model soil erosion risk in a mountainous karst watershed, Guizhou Province, China. Environ Monit Assess 141:275-286

Yan J, Wang W, Zhou C, Li K, Wang S (2014) Responses of water yield and dissolved inorganic carbon export to forest recovery in the Houzhai karst basin, southwest China. Hydrol Process 28:2082-2090

Yang L, Luo P, Wen L, Li D (2016) Soil organic carbon accumulation during post-agricultural succession in a karst area, southwest China. Sci Rep 6:37118

Yu Y, Wang K, Chen H (2009) Adaptable landscape ecology design for karst environmental emigration region. Res Agric Mod 30:90-94 (in Chinese with English abstract)

Yu D, Sun L, Yu J, Wang Z (2012) Simulation on soil erosion and streamflow in Maotiaohe Watershed of Guizhou Province based on SWAT Model. Chin Agric Sci Bull 28:256-261 (in Chinese with English abstract)

Yuan D, Cai G (1988) The science of karst environment. Chongqing Science and Technology Publishing House, Chongqing (in Chinese)

Zeng F, Peng W, Song T, Wang K, Wu H, Song X, Zeng Z (2007) Changes in vegetation after 22 years' natural restoration in the karst disturbed area in northwest Guangxi. Acta Ecol Sin 27:5110-5119 (in Chinese with English Abstract)

Zhang L, Hu B (2008) Estimation of ecosystem service value losses based on land use change in karst area: a case of Duan County. Carol Sin 27:335-339 (in Chinese with English abstract)

Zhang W, Chen H, Wang K, Su Y, Zhang J, Yi A (2006) The heterogeneity of soil nutrients and their influencing factors in peak-cluster depression areas of karst region. Sci Agric Sin 39:1828-1835 (in Chinese with English Abstract)

Zhang W, Chen H, Wang K, Hou Y, Zhang J (2007a) Spatial variability of soil organic carbon and available phosphorus in a typical karst depression, northwest Guangxi. Acta Ecol Sin 27:1-8 (in Chinese with English Abstract)

Zhang J, Su Y, Chen H, Zhang W (2007b) Dynamic change of soil moisture in karst region of Northwest Guangxi Province. Bull Soil Water Conserv 27:32-36 (in Chinese with English Abstract)

Zhang X, Wang S, He X, Wang Y, He Y (2007c) Soil creeping in weathering crust of carbonate rocks and underground soil losses on karst slopes. Earth Environ 35:202-206
Zhang X, Wang K, Chen H, Zhang W (2008a) Relationships between landscape structure and rocky desertification in karst region of northwestern Guangxi. Chin J Appl Ecol 19:2467-2472 (in Chinese with English Abstract)

Zhang M, Wang K, Chen H, Zhang C, Liu H, Yue Y, Fan F (2009a) Evaluation of ecosystem services in karst areas based on remote sensing. Acta Ecol Sin 29:5891-5901 (in Chinese with English Abstract)

Zhang M, Wang K, Chen H, Zhang C, Liu H, Yue Y, Fan F (2009b) Quantitative evaluation and analysis of ecosystem services in karst areas based on remote sensing. Acta Ecol Sin 29:5891-5901 (in Chinese with English Abstract)

Zhang X, Wang K, Zhang W, Chen H, He X (2009c) The quantitative assessment of eco-environment vulnerability in karst regions of Northwest Guangxi. Acta Ecol Sin 29:1-9 (in Chinese with English abstract)

Zhang P, Hu Y, Xiao D, Li X, Yin J (2010a) Influences of topographic parameters on changes of potential rocky desertification landscape pattern in karst plateau mountain. Chin J Soil Sci 41:1305-1310 (in Chinese with English abstract)

Zhang M, Wang K, Liu H, Chen H, Zhang C, Yue Y (2010b) Responses of ecosystem service values to landscape pattern change in a typical karst area of northwest Guangxi, China. Chin J Appl Ecol 21:1174-1179 (in Chinese with English Abstract)

Zhang M, Zhang C, Wang K, Yue Y, Qi X, Fan F (2011) Spatiotemporal variations of karst ecosystem service values and its correlation with environmental factors in Northwest Guangxi, China. Environ Manag 49:933-944

Zhang Y, Li Y, An Y, Peng S (2012a) Ecological assets evaluation in a karst mountainous area: a case study in Guiyang City. Earth Environ 40:412-416 (in Chinese with English abstract)

Zhang W, Wang K, Chen H, He X, Zhang J (2012b) Ancillary information improves kriging on soil organic carbon data for a typical karst peak-cluster depression landscape. J Sci Food Agric 92:1094-1102

Zhang F, Zhang J, Su W (2012c) Preliminary research for the influence of agricultural production activities on the landscape in karst peak-cluster. Res Soil Water Conserv 19:191-195 (in Chinese with English abstract)

Zhang W, Chen H, Su Y, Wang K, Lin H, Liu K (2013) Effects of reclamation and fertilization on calcareous soil fertility in the initial period of cultivation. Chin J Soil Sci 44:925-930 (in Chinese with English Abstract)

Zhang S, Bai X, Wang S, Qin L, Tian Y, Luo G, Li Y (2014) Ecosystem services evaluation of typical rocky desertification areas based on InVEST model: a case study at Qinglong County, Guizhou. J Earth Environ 5:328-338

Zhang M, Wang K, Liu H, Zhang C, Wang J, Yue Y, Qi X (2015a) How ecological restoration alters ecosystem services: an analysis of vegetation carbon sequestration in the karst area of northwest Guangxi, China. Environ Earth Sci 74:5307-5317

Zhang W, Zhao J, Pan F, Li D, Chen H, Wang K (2015b) Changes in nitrogen and phosphorus limitation during secondary succession in a karst region in southwest China. Plant Soil 391:77-91

Zhang M, Wang K, Liu H, Wang J, Zhang C, Yue Y, Qi X (2016) Spatio-temporal variation and impact factors for 
vegetation carbon sequestration and oxygen production based on rocky desertification control in the karst region of southwest China. Remote Sens 8:102

Zhang C, Qi X, Wang K, Zhang M, Yue Y (2017) The application of geospatial techniques in monitoring karst vegetation recovery in southwest China: a review. Prog Phys Geogr 41:450-477

Zhao G (2014) Assessing karst mountainous ecosystem service using a CLUE-S model. Master thesis: Beijing, China University of Geosciences, p 168 (in Chinese with English abstract)

Zhou Y (1997) A study on the plants' main nutrient elements contents in Guizhou Karst region. J Guizhou Agric Coll 16:11-16 (in Chinese with English abstract)

Zhou N, Li C, Jiang S, Tang Y (2009) Models of soil and water loss and soil leakage in Puding karst area. J Soil Water Conserv 29:7-11
Zhou C, Chen X, Liu X, Zhao W, Li K, Tang J (2011) Assessment of karst regional ecosystem service functions based on land use change: a case study in Guizhou, China. Chin J Appl Environ Biol 17:174-179 (in Chinese with English Abstract)

Zhu S (1993) Karst forest ecology (I). Guizhou Science and Technology Press, Guiyang (in Chinese)

Zhu H (2007) The karst ecosystem of southern China and its biodiversity. Trop For 35(supp):44-47 (in Chinese with English abstract)

Publisher's Note Springer Nature remains neutral with regard to jurisdictional claims in published maps and institutional affiliations. 